\title{
EL BIEN JURÍDICO Y LAS FUNCIONES DEL DERECHO PENAL
}

\author{
Manuel Alberto Leyva Estupiñán* \\ Larisbel Lugo Arteaga**
}

\begin{abstract}
Resumen: La dogmática penal referida a las funciones del Derecho penal y el bien jurídico penal es amplia y diversa. Con el liberalismo penal comenzó un proceso de construcción teórica del objeto de tutela del Derecho penal, que no ha concluido. La mayoría de los penalistas contemporáneos, salvo pocas excepciones, coinciden en señalar que el Derecho penal protege bienes jurídicos; sin embargo, al definir qué se entiende por bien jurídico es cuando comienzan las divergencias teóricas. El rol de la Constitución como norma suprema del ordenamiento jurídico de un país, la derivación de esta
\end{abstract}

* Profesor de Derecho Penal en la Universidad de Holguín, Cuba. Licenciado en Derecho por la Universidad de Camagüey, Cuba. Máster en Derecho Penal por la Universidad de Holguín. Actualmente cursa el doctorado en Ciencias Jurídicas por la Facultad de Derecho de la Universidad de Oriente, Cuba. Ha participado como ponente en más de una decena de eventos internacionales, y publicado varios artículos en varias revistas de corte jurídico. Profesor invitado en la República Bolivariana de Venezuela. Jefe del Departamento de Derecho, Facultad de Ciencias Sociales y Jurídicas, Universidad de Holguín, Cuba. Correo-e: mleyva@fh.uho.edu.cu. Holguín, Cuba.

** Profesora de Derecho Penal Especial en la Universidad de Holguín, Cuba. Licenciada en Derecho por la Universidad de Camaguey, Cuba. Se desempeñó como jueza en el Tribunal Provincial Popular de Camagüey en su Sala Quinta de lo Penal. Máster en Derecho Penal por la Universidad de Holguín. Correo-e: 1lugo@fh.uho.edu.cu.Holguín,Cuba.Fecha de recepción: 2 de febrero de 2015. Fecha de modificación: 29 de mayo de 2015. Fecha de aprobación: 30 de julio de 2015. Para citar el artículo: Manuel Alberto Leyva Estupiñán, Larisbel Lugo Arteaga (2015). "El bien jurídico y las funciones del Derecho penal”, en Revista Derecho Penal y Criminología, Vol. 36, n. ${ }^{\circ} 100$, enero-junio de 2015. Bogotá: Universidad Externado de Colombia, pp. 63-73. DOI: http://dx.doi.org/10.18601/ 01210483.v36n100.04 
del objeto de protección del Derecho Penal y las complejas interrelaciones que se establecen entre poder estatal, protección penal, delimitación del bien jurídico etc., constituyen algunos de los temas presentes del Derecho penal y la Filosofía penal contemporánea.

Palabras clave: Bien juíridico; ius puniendi; Derecho penal mínimo; Principio de lesividad.

\title{
THE GOOD JURIDIC AND THE FUNCTION OF THE CRIMINAL LAW
}

\begin{abstract}
The penal dogmatic referred to the shows of The Penal Law and the penal juridical good is ample and diverse. The process of theoretic construction of the object of tutelage of The Penal Law begun with the penal liberalism and its end has not come. The contemporary criminal lawyers' majority, excluding a few exceptions coincide in indicating that The Penal Law protects the juridical good, however, when defining what they understand for juridical good it is where they begin the theoretic divergences. The role of the Constitution like supreme standard of the juridical organizing of a country, the derivation of this of the object of protection of The Penal Law and the complex interrelations that become established between the state-owned power, penal protection and the delimitation of the good juridical constitute some of the present themes of The Criminal Law and the Penal contemporary Philosophy.
\end{abstract}

Key words: Good Juridic; Right to Punish; Minimal Penal Law; Principle of Damage.

\section{INICIO}

Las funciones del Derecho penal se confunden en ocasiones con las funciones de la norma jurídico-penal o las funciones de la pena. Al ser la pena la consecuencia jurídica de la conducta delictiva, las funciones propias de la sanción y las funciones del Derecho penal se interrelacionan dialécticamente. En relación con las funciones de las penas y las medidas de seguridad (contenido de esta rama del Derecho que lo define con un carácter dual), han existido desde las teorías retributivas, de la prevención ${ }^{1}$ general, especial y criterios mixtos, que son los más extendidos.

En la actualidad, es mayoritario ${ }^{2}$ el criterio que sostiene que el Derecho penal se encarga de la protección de bienes jurídicos. El Derecho penal, según Roxin, cumple una

1 Las teorías de la prevención han sido criticadas por Roxin, quien argumenta dos serias razones. 1) Hay muchos delitos en los que no se ha podido demostrar la eficacia de la pena; 2) Fundar la ejecución de la pena en la necesidad de intimidar a la colectividad supondría utilizar al condenado como instrumento, castigarle no por lo que ha hecho, sino para que los demás no delincan.

2 JАKовS (2001: 28-29) sostiene que "el Derecho penal garantiza la vigencia de la norma, no la protección de bienes jurídicos". 
doble función: protección de bienes jurídicos y de los “fines públicos de prestación imprescindibles". Visto desde otro escenario, podemos afirmar que las funciones del Derecho penal son la protección de los bienes jurídicos y la motivación de conductas respetuosas, ajustadas al orden social y jurídico establecido por normas legales.

En el estudio del bien jurídico, por lo general se considera que este constituye un límite al ius puniendi ${ }^{3}$, comúnmente aceptado como derecho a castigar del Estado, más que derecho subjetivo del Estado ${ }^{4}$ o como potestad del Estado para castigar ${ }^{5}$ a nuestro modo de ver constituye un límite en sí mismo, límite formal, pues estaríamos hablando del Estado autolimitándose en sus funciones. En nuestro criterio, el ius puniendi constituye un deber $^{6}$ generado por las propias funciones del Estado.

Las discutidas relaciones entre Derecho-ideología, Derecho-moral, Derecho-política en alguna medida pierden su razón de ser cuando se advierte que todo Derecho, y fundamentalmente el que encuentra asidero en normas positivas, es un reflejo de las aspiraciones de la clase dominante, que por intermedio del Derecho, como herramienta valiosísima, conculca en los ciudadanos su sistema de valores. Como afirma el profesor sevillano MuÑoz Conde (HAssemer y MuÑoz Conde, 1989: 111), los "bienes jurídicos son producidos". Si en el pasado se podía construir la ideología imperante a partir del dominio político de determinada clase social, hoy resulta difícil delimitar qué intereses se tutelan, pues no puede hablarse de un grupo homogéneo ideológicamente hablando. Detrás del Estado contemporáneo no son los partidos o movimientos políticos o sociales los que determinan las pautas, sino los grandes intereses económicos, mayormente trasnacionales. El Derecho penal, al definir qué

3 La concepción tradicional del ius puniendi como derecho a castigar del Estado resulta, a nuestro modo de ver, incorrecta. Desde una concepción liberal, ciertamente podría defenderse la categoría Derecho, lo cual refuerza criterios como la existencia de una relación cuasi-contractual entre Estado e individuo. ¿Por qué nace en el individuo que comete un delito la obligación de sufrir una pena? Desde una posición marxista, que niega llevar al plano contractual las relaciones Estado-sociedad civil, más que Derecho debe considerarse facultad y deber. Facultad porque solo el Estado está legitimado a través de sus órganos jurisdiccionales para dictar las leyes y perseguir a quienes cometan delitos. Constituye a la vez un deber que se sustenta en las funciones del Estado. El Estado tiene el deber de delimitar las conductas constitutivas de delito y la obligación -no derecho- a perseguirlas y sancionarlas. La razón de ser del Estado es precisamente garantizar la coexistencia, la estabilidad de la sociedad: tiene encomendado ese rol. Para poder cumplirlo de forma satisfactoria deberá prohibir y penalizar determinadas conductas, a fin de proteger de manera efectiva los bienes jurídicos políticamente importantes para la clase dominante. Cfr. Fontán BALESTRA (1998: 14-15), ZAFARONI (1998: 33 y ss.).

4 Soler (1992: 13), Mir Puig (Ob. cit.: 98), Medina Cuenca (2001).

5 NúÑEZ (1999: 15), Quintero Olivares (1976: 37) habla de "potestad punitiva”.

6 Autores como CARBOnEll Mateu plantean que "ha de considerarse indiscutible que no se trata del ejercicio de ningún derecho subjetivo, sino de las funciones que corresponden al Estado en virtud del pacto social traducido en la Constitución. El poder de crear normas penales no tiene diferentes características que el de legislar en materia de cultura, obras públicas o educación, si bien, a diferencia de esas materias, y como ya sabemos, el Derecho penal supone recortes a la libertad general con el fin de tutelar las libertades de los ciudadanos” Cfr. CARbonell Mateu (1996: 102). 
protege de manera efectiva, qué conductas sanciona, lo hace -y es lamentable que así suceda- para satisfacer al gran capital, no a las mayorías.

La discusión cae entonces en que es lo que debe ser considerado como bien jurídico. La mayoría de los autores ${ }^{7}$ difieren en la concepción sobre el bien jurídico.

Desde el punto de vista histórico, se ha asociado a los derechos subjetivos, ya criticados en su momento por MEZGER, cuando exponía ejemplos de delitos cuando no se atacaban bienes jurídicos. También ha sido considerado como interés, lo cual reduce el significado del término, pudiendo existir bienes jurídicos que no generen un interés propiamente dicho en su titular. COBO DEL RosAl y Vives ANTÓN (s.f.: 249) traen a manera de ejemplo la vida como bien jurídico y varias situaciones en las que la misma no constituya un interés para su titular.

Inicialmente, el Derecho se encargó de la tutela de bienes jurídicos individuales que coincidían con los llamados derechos constitucionales de primera generación, como son la vida, la integridad corporal, el honor, etc. Según EL-KHOURY JACOB, no se debe perder de vista que el concepto de bien jurídico que, de acuerdo con HASSEMER, "es obra del pensamiento de la ilustración”. Lo fundamentó y formuló PAUL JOHANN ANSELM FEUERBACH como "arma contra una concepción moralizante del Derecho penal". Para Roxin, el concepto se debe a BIRNBAUM ${ }^{8}$. Con este autor aparece un nuevo punto de partida en la idea de un concepto de bien jurídico, no netamente subjetivo, porque parte de la premisa que detrás de ese derecho hay algo más que se quiere proteger, un interés que es su razón de ser y que surge a partir de un concepto natural y positivo del derecho. BIRNBAUM les da un vuelco a estas consideraciones, al sostener que debían de ser bienes tutelados por el Estado.

FERRAJOLI parte de un análisis sobre lo que merece tutela penal, en sus distintas etapas, partiendo de los iluministas (Feuerbach y Humboldt, DE Bentham y ConCorCet, Filangieri, Romagnosi, PAgAno y CARMignani), para quienes debía ser necesariamente un derecho subjetivo natural de la persona.

Los idealistas objetivos, con su máxima figura, GuILlERMo FEDERICO HegEL quien, abstrayéndose de "lo que es justo en su existencia" al "derecho en sí", de la parte lesionada "al universal lesionado", caminan por senderos idealistas que no representan la verdadera magnitud del concepto de bien jurídico. Resulta entendible si partimos de que el Derecho es una parte más de la superestructura social, asentada sobre determinada base económica.

7 Juares (s.f.: 67), Ferrajolli (s.f.), Chirinos SÁnchez (s.f.), Roxin (1997: 55), Birnbaum (1834), Birnbaum (2010), De La Cuesta Aguado (s.f.), SuÁrez López (2009), Bustos Ramírez y HormaZÁBAl MALARÉE (1997: 58).

8 Para el profesor QuIROs PÍREZ (2005: 182), la construcción del bien jurídico es anterior a BIRNBAUM. 
IHERING y BINDING lo analizan sobre la base de lo que "pueda servir al interés del Estado" o lo que" tiene valor a los ojos del legislador". El bien jurídico, desde una función utilitarista, se identifica con la validez de la norma. Desde esa perspectiva, el bien jurídico es entendido como "un valor de la persona humana de carácter universal, material o ideal, pero real, y que se lo describe como la relación de disponibilidad de un sujeto para con un objeto".

Para JESCHECK, el bien jurídico ha de entenderse como valor ideal del orden social jurídicamente protegido, en cuyo mantenimiento tiene interés la comunidad y que puede atribuirse, como su titular, tanto al particular como a la colectividad. En cuanto categoría puramente formal, el bien jurídico es además el género de todos los "objetos individuales que incluye el fin de protección de la norma" (EsTRADA VÉLEZ, 1998: 181).

Como afirma Ferrajoli (ídem: 7), el problema del bien jurídico no es otra cosa que el problema de los fines del Derecho penal. Para el eminente penalista italiano, "un programa de Derecho penal mínimo debe entonces apuntar hacia una masiva deflación de los bienes penales actualmente tutelados por la ley, por lo tanto, a una drástica reducción de las prohibiciones legales, como condición de su legitimidad política y jurídica". A partir de lo que hoy conocemos como principio de lesividad u ofensividad, no tiene razón de existir un Derecho penal que no lesione o al menos ponga en peligro bienes jurídicos. “(...) el bien jurídico es el criterio central para determinar el merecimiento de pena que, para salvaguardar, de algún modo los derechos de las distintas partes intervinientes en un conflicto penal" (CASELL LóPEZ, 2004).

El profesor Roxin considera que "el bien jurídico, por tanto, es el bien ideal que se incorpora en el concreto objeto de ataque; y es lesionable solo dañando los respectivos objetos individuales de la acción" (ídem: 63). El penalista alemán lo considera como "circunstancias dadas o finalidades que son útiles para el individuo y su libre desarrollo en el marco de un sistema social global estructurado sobre la base de esa concepción de los fines o para el funcionamiento del propio sistema" (ídem: 56). Para declarar una conducta como delito, no debería bastar que suponga una infracción de una norma ética o divina, es necesario ante todo la prueba de que lesiona intereses materiales de otras personas, es decir, de que lesiona bienes jurídicos" (HASSEMER, 1984: 37). ZAFFARONI (1989: 289) lo define así: “...bien jurídico penalmente tutelado es la relación de disponibilidad de un individuo con un objeto, protegida por el Estado, que revela su interés mediante la tipificación penal de conductas que le afectan”.

Cuando JAKOBS contrapone la vigencia de la norma como función del Derecho penal a la concepción predominante ${ }^{9}$ enfocada en la protección de bienes jurídicos, nos

9 Cfr. Roxin (1997: 52), Bacigalupo (1996: 6), JoACHimrudolPhi (1991: 82), Mir Puig (2003: 147), ZAFFARONI (1998: 24), QUIRÓs PíREZ (1999: 158). 
recuerda al maestro KELSEN, quien en una de sus obras cumbres, La Teoría pura del Derecho (1935), defendió el concepto del Derecho como entidad autónoma de concepciones ideológicas y morales. Como hemos reiterado, nuestra visión del bien jurídico parte de considerarlo como aspiraciones, valores, ideales, que no existen independientes de la realidad, sino que son condicionados por ella, manifestándose en las fundamentales relaciones sociales que se producen. No puede concebirse el Derecho como un ente abstracto. La norma, por encima de cualquier otra consideración, lleva en sí los valores y aspiraciones del grupo políticamente dominante en la sociedad.

Por bienes jurídicos entiende CALLIESS no "substanciales" (Substanzialen) ni "valores" o "bienes", sino "participantes" (Partizipalien). Protección de bienes jurídicos significa "protección de las posibilidades de participación en la sociedad". La estructura que protege el Derecho penal garantiza la seguridad de comportamiento y de expectativas para el sujeto activo y el sujeto pasivo: se sabe cómo hay que comportarse y cabe esperar que el otro se comportará en consecuencia (MIR PUIG, 2003: 72).

Cobo del Rosal y Vives Antón (Op. cit.: 249) consideran de manera sintética que constituye todo valor de la vida humana protegido por el Derecho.

MuÑoz CONDE (1975: 91) plantea que son los presupuestos que la persona necesita para la autorealización en la vida social.

Desde otro punto de vista, puede valorarse de la siguiente manera:

1. En el sentido político criminal: (de lege ferenda) aquello que merece ser protegido por el Derecho penal.

2. En el sentido dogmático: (de lege data) objeto efectivamente protegido por la norma penal vulnerada de que se trate.

En la actual sociedad del riesgo, algunos autores (ídem: 2) al valorar las críticas ${ }^{10}$ que se formulan a la teoría del bien jurídico, algunas de ellas desde una multiplicidad de definiciones, centran el debate en torno al surgimiento del bien jurídico. La primera de las posiciones parte de su consideración como objeto de protección del Derecho penal (siendo la protección de bienes jurídicos y la motivación las principales funciones que se le reconocen al mismo), debe la existencia a partir del reconocimiento por el Derecho positivo. Consideramos que más que objeto, los bienes jurídicos constituyen el conjunto de valores, intereses y aspiraciones de los individuos y la sociedad.

10 KаковS afirma que la verdadera función del Derecho penal no es la protección de bienes jurídicos, sino la protección de la vigencia de la norma. 
Lo anterior legitima la despenalización de aquellas conductas que no representan un riesgo real y grave ${ }^{11}$ a la humanidad.

Los estudiosos (KIERSZENBAUn, 2009: 1-2) que siguen las premisas de Von LiSZT consideran al bien jurídico como un interés vital preexistente al ordenamiento jurídico.

En nuestra modesta opinión, hablar de bien equivale necesariamente a hablar de valor, pero no todo valor relevante al Derecho constituye bien jurídico penal. Los principios de ultima ratio y lesividad, limitadores al ius puniendi del Estado, condicionan determinados requisitos para que un valor o interés sea tutelado por el Derecho penal. Ese valor debe representar una derivación de los valores superiores recogidos en la Constitución, no solo norma jurídica suprema, sino también proyecto político aspirado. Así como esta categoría ha de desprenderse de los valores defendidos en la Constitución, es menester aclarar que dichos valores, así como los bienes finalmente tutelados, podrán ser siempre objeto de discusiones, tanto por ausencias como por excesos. Discusiones estas que olvidan el carácter clasista del Estado y el Derecho: al responder a una ideología determinada, el legislador no hace sino proteger aquellos intereses del grupo dominante. Cierto es que pueden ocurrir desfases temporales con los valores defendidos por la propia ideología, pero finalmente las modificaciones en la norma positiva suplen estas las carencias. Termina así el Estado siendo también objeto de tutela del Derecho penal ${ }^{12}$.

En la doctrina cubana contemporánea, QuiRós PíREZ, al igual que el español BusTos RAMíREZ, se afilia a la teoría de la relación social como sustento del bien jurídico Magister dixit al referirse al concepto como "las relaciones sociales o elementos de las relaciones sociales que, por su particular interés social, son protegidas por medio del Derecho penal, de los ataques y amenazas materializados por comportamientos considerados socialmente peligrosos" (Quirós Pírez, 1999: 118). Por tanto, resulta atinado ubicar la estrecha relación entre bien jurídico y antijuricidad. Las relaciones sociales más importantes para la sociedad no adquieren la condición de bien jurídico per se, sino que necesitan estar tuteladas por una norma penal.

Desde una función sistemática, permite valorar la lesión o el peligro a que ha sido sometido, lo que lleva a que asuma un rol dentro del ilícito penal, no ya como elemento en la estructura del tipo penal o que permita la configuración de familias delictivas, sino como requisito sine qua non. Sin ataque al bien jurídico no existe delito.

11 Esta idea concreta la concepción del Derecho penal, como un Derecho de ultima ratio. También explica una de las funciones del bien jurídico: la interpretación. Por tanto, el Derecho penal, como última de las opciones, protege subsidiariamente los bienes jurídicos defendidos también por otras ramas.

12 Los delitos contra la Seguridad del Estado, contra la economía nacional, contra la administración y jurisdicción, por solo citar algunos ejemplos, manifiestan bien de manera directa o bien de manera accesoria, la condición del Estado como objeto del tutela del Derecho penal. 
El autor coincide con lo expresado por el profesor de Múnich (Roxin, 1997: 55) con respecto a la derivación de los bienes jurídicos de la Constitución, en tanto esta plasma los límites al poder punitivo del Estado. Valorar la derivación constitucional de los bienes jurídicos tutelados por normas penales implica asumir que los movimientos constituyentes reflejan conquistas sociales llevadas al plano jurídico con una fuerte carga axiológica, pero también intereses económicos, políticos e ideológicos. La existencia de cláusulas pétreas en las constituciones o el posterior inmovilismo a la hora de dictar las normas complementarias a la Carta Magna, reflejan dónde está el poder real, y es este poder el que decide qué y cómo castigar.

Los principios de ultima ratio y lesividad, limitadores al ius puniendi del Estado condicionan determinados requisitos para que un valor o interés sea tutelado por el Derecho penal. Ese valor debe representar una derivación de los valores superiores recogidos en la Constitución, no solo norma jurídica suprema, sino también proyecto político aspirado. Así como esta categoría ha de desprenderse de los valores defendidos en la Constitución, es menester aclarar que dichos valores, así como los bienes finalmente tutelados, podrán ser siempre objeto de discusiones, tanto por ausencias como por excesos. Discusiones estas que olvidan el carácter clasista del Estado y el Derecho; al responder a una ideología determinada, el legislador no hace sino proteger aquellos intereses del grupo dominante. Cierto es que pueden ocurrir desfases temporales con los valores defendidos por la propia ideología, pero finalmente las modificaciones en la norma positiva suplen estas las carencias. Termina así el Estado siendo también objeto de tutela del Derecho penal ${ }^{13}$.

Nuestra visión del bien jurídico parte de considerarlo como aspiraciones, valores, ideales, que no existen independientes de la realidad, sino que son condicionados por ella, manifestándose en las fundamentales relaciones sociales que se producen. No puede concebirse el Derecho como un ente abstracto. La norma, por encima de cualquier otra consideración, lleva en sí los valores y aspiraciones del grupo políticamente dominante en la sociedad. Desde un enfoque indirecto, al proteger bienes jurídicos de naturaleza penal, se está garantizando la estabilidad política y social del sistema.

\section{BIBLIOGRAFÍA}

Asúa Batarrita, Adela (1990). "Reivindicación o superación del programa Beccaria”, en Asúa Batarrita, Adela (ed.). El pensamiento penal de Beccaria: su actualidad. Bilbao: Ed. Universidad de Deusto.

13 Los delitos contra la Seguridad del Estado, contra la economía nacional, contra la administración y jurisdicción, por solo citar algunos ejemplos, manifiestan bien de manera directa o bien de manera accesoria, la condición del Estado como objeto del tutela del Derecho penal. 
Bacigalupo, EnRiQue (1996). Manual de Derecho Penal, tercera reimpresión. Santa Fe de Bogotá: Editorial Temis.

BIRNBAUM, ÜBER (1834). Das Erfordernis einer Rechtsverletzung Zum Begrif des Verbrechens en Archiv des Criminalrechts, Neue Folge.

Birnbaum, Johannn Michael Franz (2010). Sobre la necesidad de una lesión de derechos para el concepto de delito. Colección Maestros del Derecho Penal, ed. BdF, n. ${ }^{\circ} 32$.

Bustos Ramírez, Juan J. y Hormazábal Malarée, Hernán (1997). Lecciones de Derecho Penal. Volumen I. Madrid: Editorial Trotta.

Carbonell Mateu, Juan Carlos (1996). Derecho penal: concepto y principios constitucionales. 2a ed., adaptada al Código Penal de 1995. Tirant lo blanch.

Casell López, Magaly (2004). La Política Criminal. Colectivo de autores. La Habana: Ed. Félix Varela. Citando Hans Jescheck HeInRICH (1986). "Nueva Dogmática y Política Criminal en Perspectiva comparada", en Anuario de Derecho penal y Ciencias penales, Tomo 39, Fascículo I.

Cobo Del Rosal, M. y Vives Antón, T. M. (s.f.). Derecho Penal: Parte General, 3ra. Edición corregida y actualizada. Tirant lo Blanch.

Chirinos SÁnchez, Alfredo y Henry Issa El-Khoury Jacob (s.f.). "Bien jurídico y derecho de castigar del Estado". Comentarios sugeridos por una sentencia de la Sala Constitucional, en Revista de la Sociedad de Ciencias Penales de Costa Rica.

De La Cuesta Aguado, Paz M. (s.f.). Norma primaria y bien jurídico: su incidencia en la configuración del injusto (VII).

Estrada Vélez, Federico (1998). Derecho penal Parte General. Editorial Hammurabi S.R.L., 2. a edición.

FERrajoli, Luigi (1995). Derecho y Razón. Teoría del garantismo penal. Editorial Trotta.

FERrajoli, Luigi (s.f.). “Derecho penal mínimo y bienes jurídicos fundamentales”, en Revista Ciencias Penales. San José: Asociación de Ciencias Penales de Costa Rica. Disponible en http://www.cienciaspenales.org/ferraj05.html. Consultado el 17 de junio del 2014.

Fontán Balestra, Carlos (1998). Derecho Penal. Introducción y Parte General. Buenos Aires: Abeledo-Perrot. 
García Pablos, Antonio (2000). “Tendencias del Actual Derecho Penal”. Modernas Tendencias en la ciencia del Derecho Penal y en la Criminología. Universidad Nacional de Educación a Distancia. Congreso Internacional, Actas y Congresos. Madrid. España.

Hassemer y Muñoz Conde (1989). Introducción a la Criminología y al Derecho Penal. España: Ed. Tirant lo Blanc.

Hassemer, Winfried (1984). Fundamentos del Derecho Penal. Barcelona: Editorial Bosch.

Jakobs, GüNTHer (2001). ¿Qué protege el Derecho Penal: bienes jurídicos o la vigencia de la norma. Argentina: Ediciones Jurídicas Cuyo.

JoACHIMRUDOLPHI, HANS (1991). "El fin del Derecho penal del Estado y las formas de imputación jurídico-penal", en El sistema moderno del Derecho penal: Cuestiones fundamentales. Estudios en honor de Claus Roxin en su 50 Aniversario. Compilado por BERND SCHÜNEMANN. Introducción, traducción y notas de Jesús-MARÍA SILVA SÁNCHEZ. Madrid: Editorial Tecnos.

Juares, E.X. TAVArez (s.f.). Bien jurídico y función en el Derecho penal, colección Claves del Derecho Penal, n. ${ }^{\circ}$, ed. Hammurabi.

Kierszenbaun, Mariano (2009). "El bien jurídico en el Derecho Penal . Algunas nociones básicas desde la óptica de la discusión actual", en Lecciones y ensayos. n. ${ }^{\circ} 86$. pp. 1 y 2 . Disponible en http://www.derecho.uba.ar/publicaciones/lye/revistas/86/07ensayo-kierszenbaum.pdf. Consultado el 8 de septiembre de 2014.

Medina Cuenca, Arnel (2001). Los principios limitativos del ius puniendi. Su incidencia en la determinación de la pena y su consagración en las constituciones nacionales y en los instrumentos jurídicos adoptados por la comunidad internacional. Trabajo de investigación defendido en opción del título de Master en Derecho público, en el Departamento de Derecho Penal de la Facultad de Derecho de la Universidad de Valencia, España.

Mir Puig, Santiago (2003). Introducción a las bases del Derecho Penal". 2. a ed. Buenos Aires: Euros Editores S.R.L.

NúÑEZ, Ricardo C. (1999). Manual del Derecho Penal Parte General. Cuarta Edición Actualizada por RoberTo E. SPINKA y FéLIX GonZÁLEZ. Argentina: Editorial Córdoba.

Quintero Olivares, G. (1976). Represión penal y Estado de Derecho. Barcelona. 
Quirós Pírez, Renén (1999). Manual de Derecho Penal. Parte General. Tomo i. La Habana: Editorial Felix Varela.

SÁnchez, Alfredo y Henry IsSa El-Khoury JaCOB (s.f.). "Bien jurídico y derecho de castigar del Estado. Comentarios sugeridos por una sentencia de la Sala Constitucional", en Revista de la Sociedad de Ciencias Penales de Costa Rica.

Soler, Sebastián (1992). Derecho Penal Argentino. Buenos Aires: Tipográfica Editora Argentina.

SuÁrez LóPez, BEATRIz Eugenia (2009). ¿Existe el bien jurídico-penal en el siglo XXI? Premio Francisco Tomás y Valiente de la Universidad de Barcelona.

Roxin, Claus (1997). Derecho Penal. Parte General Tomo i. Fundamentos. La estructura de la teoría del delito. Traducción de la 2da. edición alemana. Madrid: Editorial Civitas SA.

Zaffaroni, Eugenio Raúl (1989). Manual de Derecho Penal. Buenos Aires: EdiAR.

Zaffaroni, Eugenio Rául (1999). Tratado de Derecho Penal. Parte General. Tomo I. Ediar. Argentina 1998,p 24. Quirós PíreZ, REnéN; “Manual de Derecho Penal. Tomo I. La Habana: Editorial Félix Varela, 1999. 
